\title{
Made in Brazil
}

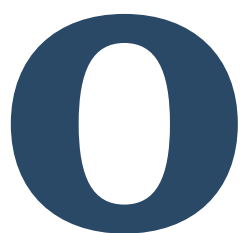

marketing de produtos não é um tema restrito a empresas e empresários, nem uma questão baseada apenas no valor intrínseco do produto. Envolve iniciativas bem mais amplas. A Certificação de Origem de produtos é uma delas. Esse "selo" funciona como um certificado de originalidade e diferenciação e permite uma ampliação do valor embutido. Assim, ganha status de segunda marca e podelevar os consumidores a pagarem preços premium por produtos que o exibem.

por Rubens da Costa Santos FGV-EAESP

Em mercados competitivos e dinâmicos, apenas al guns produtos, por serem produzidos em determinadas regiões ou países, possuem uma nítida vantagem sobre seus concorrentes. Eles compõem um seleto grupo, casos exemplares de sucesso e prestígio internacional, são únicos e diferenciados. Os consumidores mais exigentes os procuram com determinação e costumam pagar preços acima da média para adquiri-los. Essa clientela compra tais especiarias em ambientes requintados, e não dispensa a ambientação e os rituais de consumo.

0 vinho do Porto, por exemplo, é produzido em uma determinada região de Portugal e em nenhum outro lugar do 
mundo. 0 mesmo acontece com o champagne, oriundo da região de mesmo nome na França. 0 azeite de oliva espanhol eo perfume francês também são exemplos de produtos com fama internacional. Eles atraem as preferências dos consumidores mais exigentes e são consumidos em todo o mundo por possuírem características distintas. Ao longo dos anos, desenvolveram uma imagem diferenciada no mercado mundial. Constituem, por isso, casos de sucesso de exportação, geram saudáveis retornos para os produtores e, é claro, produzem apreciadas divisas para seus países. Esses produtos são também exemplos bem-sucedidos da Certificação de Origem (CO).

\section{Em mercados competitivos e dinâmicos,}

\section{alguns produtos, por serem produzidos}

\section{em determinadas regiões ou países,}

\section{possuem uma nítida vantagem}

\section{competitiva sobre seus concorrentes.}

para estabelecer um vínculo entre a origem e a fabricação do produto com características singulares, tal associação repercutirá positivamente nas decisões de compra dos consumidores.

As vantagens proporcionadas pela CO são desenvolvidas a partir da existência de três condições: primeiro, a existência de mão-de-obra com al gum conhecimento ou habilidade especial, como na produção detapetes persas, de pastas italianas ou de roupas femininas francesas; segundo, a excelência da matéria-prima devido a condições climáticas e geográficas, como na produção do cafécolombiano, dos vinhos franceses e dos diamantes da África do Sul; e terceiro, o domínio de tecnologias específicas, como no desenvolvimento desoftwares de uso militar dos Estados Unidos e na produção de trens de alta velocidade na França e no Japão. A CO ideal seria aquela que congrega, simultaneamente, essas três qualificações.

Os produtores que desejarem obter uma CO devem ainda ser capazes de demonstrar a superioridade de seu produto em relação ao do concorrente na mesma categoria e de mostrar que essa superioridade está fortemente associada a fatores geográficos.

In vino veritas. Quando se trata de $\mathrm{CO}$, um

No caso do Brasil, em que as exportações constituem fator crítico e indispensável para o crescimento sustentado, torna-se um desafio decisivo a identificação de produtos ea utilização de estratégias de marketing que permitam divulgá-los ao mundo. Nesse sentido, a CO poderá contribuir para aumentar as exportações. Mais adiante vamos analisar os principais conceitos da CO - o madein - eapresentar casos reais decriação de produtos com essa certificação, no Brasil eno mundo.

Entendendo a certificação. CO é um sinal emitido pelas empresas com o objetivo de garantir efortalecer as vantagens competitivas para seus produtos e serviços. Apresenta duas dimensões: a identificação de procedência (IP) e a denominação de origem (DO).

Com a globalização e a modernização dos mercados, marcadas pelo amplo acesso a produtos oriundos de todas as partes do planeta, é possível que os países se especializem na elaboração de itens para os quais tenham desenvolvido competências distintas. Se essas competências forem suficientes caso exemplar éo da produção e comercialização de vinhos. 0 exemplo da CO de vinhos permite apresentar as principais possibilidades de exploração do conceito.

Basicamente, existem seis estratégias para se explorar 0 conceito de CO no caso do vinho: na primeira, destaca-se apenas o produtor das uvas; na segunda, o produtor do vinho; na terceira, o responsável pelo marketing do vinho; na quarta, a ação conjunta dos produtores de uvas e do vinho; na quinta, o esforço conjunto do produtor do vinho e o responsável pelo marketing; e, por fim, na sexta, uma combinação de esforços do produtor das uvas, do produtor do vinho e o responsável pelo marketing do produto.

Q ualquer que seja a opção de escolha da estratégia de exploração da CO, caberá sempre ao consumidor decidir se vale a pena ou não adquirir o produto, tendo em vista sua proposta de valor.

Em termos gerais, essa proposta deverá apresentar uma combinação única, contemplando a qualidade, o preço e a origem do vinho e das uvas. 
Vale lembrar que a estratégia de destaque da área de origem de um vinho não será bem-sucedida se, ao ser desenvolvida, for apoiada apenas em ações de marketing restritas à empresa. É preciso também garantir suporte institucional. Produtores de vinho, aliados a governantes inovadores, poderão desenvolver ações conjuntas voltadas para promover e proteger seus interesses.

In Terra Brasilis. No Brasil, existem alguns produtos que já são tradicionalmente vinculados à região em que foram produzidos. Razões históricas, tradições e traços culturais contribuem para o reconhecimento nacional do churrasco gaúcho, dos laticínios de Minas, das aguardentes de Parati, dos bordados de I bitinga, das frutas tropicais do N ordeste, das malhas de Santa Catarina, das castanhas do Pará, do guaraná da Amazônia, dos acarajés da Bahia e dos cafés de diferentes regiões.

Embora as indicações de procedência sejam ainda raras no Brasil, a utilização de selos de qualidade vem, pouco a pouco, ganhando espaço. O Selo de Qualidade do Palmito, desenvolvido pelos produtores por meio da Associação Brasileira de Produtores de Palmito, e o selo de garantia da Associação Brasileira das Indústrias de Massas Alimentícias (Abima) constituem exemplos significativos de avanços nesse sentido. A recente outorga, pelo Instituto Brasileiro de Propriedadelntelectual (Inpi), do primeiro registro de procedência geográfica do Brasil para os produtores do Vale dos Vinhedos é outra importante conquista.

Mais um caso exemplar é dado pelos produtores de café de Minas Gerais. Em 1993, os produtores do cerrado mineiro criaram o Conselho das Associações dos Cafeicultores do Cerrado (Caccer), sediado em Patrocínio. 0 grupo congregou os produtores e as várias associações existentes da região. Por meio desse esforço pioneiro, as regiões mineiras produtoras de café foram identificadas e demarcadas, o que culminou com o lançamento da marca "Café do Cerrado". Desde então, o Caccer vem desenvolvendo, de forma consistente, ações mercadológicas visando à divulgação da marca em eventos locais e internacionais.

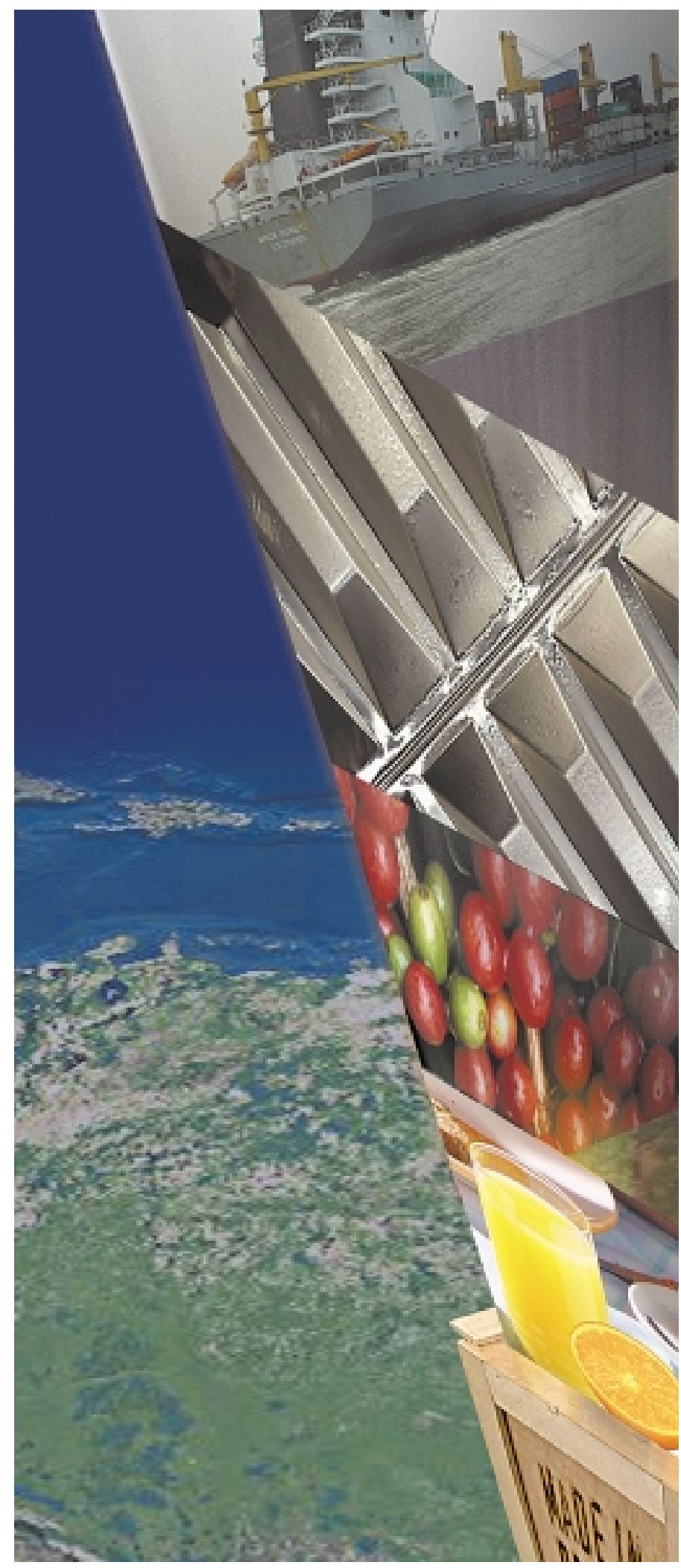


Nosso país poderia aumentar de forma

\section{consistente suas exportações caso realizasse}

\section{um esforço estruturado para o desenvolvimento}

de certificados de origem.

Marca Brasil. A imagem do país de origem pode influenciar a atitude dos consumidores. Produtos de países com imagem favorável são, em geral, avaliados positivamente. Em razão disso, ao longo do tempo, deve-se procurar garantir que os produtos exportados atendam a padrões mínimos de qualidade. No caso de empresas de países cuja imagem seja desfavorável, deve-se tomar ações que envolvam governo, representantes da cadeia produtiva e da distributiva para neutralizar os aspectos negativos da imagem.
No Brasil, alguns exportadores vêm apontando a necessidade de desenvolvimento de uma marca própria. Vários consórcios de exportação apostam na inclusão da marca do país nos produ-

tos destinados a mercados internacionais, como no caso da exportação de frutas brasileiras para a Europa.

O Brasil possui vários produtos e serviços com potencial para certificação. São fortes candidatos para CO os produtos típicos locais, como o guaraná, as frutas tropicais, o café, os queijos e doces de leite mineiros, a cocada, o vatapá ou o acarajé da Bahia. Eles são, de fato, verdadeiros símbolos brasileiros, facilmente notados pel os visitantes estrangeiros.

Tomadas as medidas adequadas, a moda brasileira pode,

\section{A receita dos especialistas}

Como fomentar o uso de certificados de origem no Brasil? Para responder a essa pergunta, entrevistamos 20 profissionais com atuação nas áreas de produção e distribuição de alimentos. 0 foco das entrevistas foram os cafés especiais, produtos de alta qualidade e margens atraentes. Com base em sua experiência, eles indicaram as seguintes iniciativas:

- Pensar em médio prazo e de forma sistêmica: desenvolver um plano integrado, com ações e responsabilidades bem definidas.

- Criar um glamour para esses produtos, estimulando seu conhecimento, seu preparo com cuidados e utensílios especiais e a ritualística em volta deles.

- Educar o consumidor das classes mais altas por meio de degustação em pontos escolhidos.

- Escolher inicialmente pontos diferenciados e evitar os pontos mais tradicionais.

- Concentrar esforços nos grandes centros de consumo. Jamais oferecer esses cafés em pontos ou mercados periféricos.

- Engajar produtores, autoridades e outros agentes no processo.

- Criar mecanismos para atrair os distribuidores e preparadores escolhidos. Cafés especiais necessitam de atenção e cuidados também especiais, seja para sua exposição e distribuição, seja para operar os sofisticados equipamentos usados em sua preparação.

- Concentrar esforços na produção. Cafés especiais devem ser elaborados com técnicas específicas, controladas, certificadas e monitoradas. Os melhores produtores devem ser valorizados, da mesma forma que as punições devem ser aplicadas aos que não atenderem aos padrões de qualidade.

- Identificar e envolver aliados da área de alimentos, compreendendo produtos, profissionais e empresas. Todos os envolvidos na cadeia produtiva devem participar do esforço. Cada elo da cadeia deve perceber ganhos na abordagem conjunta.

- Desenvolver e produzir localmente itens e máquinas atualmente importados.

- Desenvolver mecanismos para facilitar as atividades de suporte, particularmente a aquisição e manutenção das máquinas necessárias para sua preparação. 
em futuro breve, constituir caso desucesso em termos deCO 0 crescimento da visibilidade dos estilistas brasileiros e de suas criações no mundo da moda traz oportunidades interessantes para negócios de exportação. Não seria então o momento adequado para a criação de uma identidade para a moda nacional? De fato, essa possibilidade foi levantada e debatida em recente edição do São Paulo Fashion Week. A Cori, por exemplo, planeja desenvolver no exterior uma loja inteira made in Brazil.

Para que nosso país e seus empresários explorem de forma mais efetiva seu potencial exportador, é preciso fomentar ações conjuntas para a criação de certificados de origem. Devemos ouvir os agentes envolvidos e criar con- dições estratégicas, que não se resumem à empresa, para 0 desenvolvimento de marcas nacionais capazes de competir no mercado internacional.

Artigo baseado na pesquisa "Explorando o potencial de uso do Made in...no Brasil" (Relatório de Pesquisa n. 23/2002) parcialmente apoiada pelo N PP-FGV-EAESP.

Rubens da Costa Santos

Prof. do Departamento de Marketing FGV-EAESP

$\mathrm{PhD}$ em Marketing pela University of Texas

E-mail: rcsantos@fgvsp.br

\section{Olhando para fora}

Nesta entrevista, cedida à RAE- executivo, Ângela Hirata, diretora de Comércio Exterior da Alpargatas, fala sobre como a empresa está conquistando o mercado exterior.

A Alpargatas tem hoje um modelo de exportação?

Sim, temos um modelo que é baseado em nossa estratégia de comércio exterior, de não sermos produtores de marcas de terceiros. Exportamos sempre tendo como pressuposto o posicionamento de nossas marcas made in Brasil.

Quais foram os fatores que a senhora identifica como decisivos para que sua empresa conseguisse exportar? Dois fatores importantes devem ser destacados: primeiro, possuir um produto adequado ao mercado internacional; segundo, ter um staff bastante seleto de funcionários que trabalham com distribuidores-clientes em perfeita sintonia, operando como se fossem uma extensão ou prolongamento da própria Alpargatas. Esses parceiros estão espalhados hoje em 53 países.

0 que os impede de exportar mais?

No caso das Havaianas, não existe nenhum impedimento para exportarmos mais. 0 que existe é que temos uma estratégia de posicionar a marca primeiro, e a exportação acaba sendo mais seleta até que essa consolidação ocorra. Estamos entrando no terceiro ano desse trabalho, e a partir da coleção que lançamos este mês é que vamos abrir mais o leque das exportações, em busca de maior volume de vendas, embora sempre cuidando para manter o mercado high end com produtos diferenciados e customizados.
A senhora acredita que os produtos brasileiros são bem avaliados e apreciados pelo público internacional? Qual é a experiência de sua empresa nesse sentido?

0 produto brasileiro, como qualquer outro produto de outra nacionalidade, desde que atenda à necessidade do mercado-alvo, é bem apreciado. 0 importante é saber detectar o target de cada mercado para seu produto. Para tanto, o grande segredo é conseguir um distribuidor que conheça bem o seu mercado.

A senhora acha que a origem de um produto, como vindo de um determinado país, influencia na compra desse produto e em seu sucesso no mercado internacional?

Com certeza sim, mas, contanto que você consiga transmitir 0 conceito da marca de seu produto, e que esse conceito se consolide em cada país, a origem não representa uma influência tão significativa, e sim a marca e o produto.

Que recomendações a senhora deixaria para os empresários brasileiros que querem exportar mais?

Conhecer bem seu produto; buscar seu nicho de mercado; posicionar muito bem seu produto; adotar uma postura ativa, antecipando-se às necessidades de seus clientes, e não uma postura passiva, deixando-se comprar. Por fim, saber escolher seu parceiro em cada país, que entenda a política e a estratégia da empresa, que de fato trabalhe como uma extensão da empresa em seu país, expondo de forma correta o produto representado.

Por Pedro F. Bendassolli: pedrofernando@terra.com.br 